\title{
Excitation of equatorial Kelvin and Yanai waves by tropical cyclones in an ocean general circulation model
}

\author{
R. L. Sriver ${ }^{1}$, M. Huber ${ }^{2}$, and L. Chafik ${ }^{3}$ \\ ${ }^{1}$ Department of Atmospheric Sciences, University of Illinois at Urbana-Champaign, Urbana, Illinois, USA \\ ${ }^{2}$ Purdue Climate Change Research Center and Department of Earth, Atmospheric, and Planetary Sciences, Purdue University, \\ West Lafayette, Indiana, USA \\ ${ }^{3}$ Department of Meteorology/Physical Oceanography, Stockholm University, Stockholm, Sweden
}

Correspondence to: R. L. Sriver (rsriver@illinois.edu)

Received: 24 August 2012 - Published in Earth Syst. Dynam. Discuss.: 6 September 2012

Revised: 3 January 2013 - Accepted: 7 January 2013 - Published: 16 January 2013

\begin{abstract}
Tropical cyclones (TCs) actively contribute to the dynamics of Earth's coupled climate system. They influence oceanic mixing rates, upper-ocean heat content, and air-sea fluxes, with implications for atmosphere and ocean dynamics on multiple spatial and temporal scales. Using an ocean general circulation model with modified surface wind forcing, we explore how TC winds can excite equatorial ocean waves in the tropical Pacific. We highlight a situation where three successive TCs in the western North Pacific region, corresponding to events in 2003, excite a combination of Kelvin and Yanai waves in the equatorial Pacific. The resultant thermocline adjustment significantly modifies the thermal structure of the upper equatorial Pacific and leads to eastward zonal heat transport. Observations of upper-ocean temperature by the Tropical Atmosphere Ocean (TAO) buoy array and sea-level height anomalies using altimetry reveal wave passage during the same time period with similar properties to the modeled wave, although our idealized model methodology disallows precise identification of the TC forcing with the observed waves. Results indicate that direct oceanographic forcing by TCs may be important for understanding the spectrum of equatorial ocean waves, thus remotely influencing tropical mixing and surface energy budgets. Because equatorial Kelvin waves are closely linked to interannual variability in the tropical Pacific, these findings also suggest TC wind forcing may influence the timing and amplitude of El Niño events.
\end{abstract}

\section{Introduction}

Tropical cyclones (TCs) are important contributors to the dynamics of Earth's coupled system. They regulate global atmospheric and oceanic heat budgets by influencing surface heat fluxes (Trenberth and Fasullo, 2007), altering upperocean temperature patterns and mixing rates (Sriver and $\mathrm{Hu}-$ ber, 2007; Vincent et al., 2012), and redistributing heat in the ocean (Manucharyan et al., 2011; Scoccimarro et al., 2011) and atmosphere (Sobel and Camargo, 2005) with remote effects on mid-latitude weather on inter-seasonal time scales (Hart, 2011). Because trends in TC activity are generally linked to basin-scale surface temperature variability (Emanuel, 2005; Sriver and Huber, 2006) and inter-basin surface temperature differences (Vecchi et al., 2008), feedbacks may exist in the coupled system. These feedbacks have been shown to be potentially important in maintaining past climates with characteristics much different than present conditions, such as permanent El Niño-like conditions of the early Pliocene (Fedorov et al., 2010) or the unusually warm conditions during the Eocene (Korty et al., 2008). However, the role of TCs in the context of anthropogenic climate change is largely unexplored.

From the perspective of TC implications on global ocean dynamics, an early hypothesis suggested TCs may significantly contribute to maintaining the meridional overturning circulation and poleward heat transport through enhanced vertical mixing in the upper ocean (Emanuel, 2001). While recent observational studies indicate TCs are important contributors to upper-ocean tropical mixing budgets (Sriver and 
Huber, 2007; Sriver et al., 2008), several modeling studies suggest this mixing has a relatively small effect on poleward ocean heat transport (Hu and Meehl, 2009; Jansen and Ferrari, 2009; Sriver et al., 2010), unless TC forcing (e.g. surface winds) is increased substantially compared to typical present-day values (Sriver and Huber, 2010).

Due to the distribution of TCs in space and time, along with regional differences in background ocean conditions, these events now appear to be more closely linked to tropical heat convergence via the relatively shallow subtropical overturning (Pasquero and Emanuel, 2008; Jansen and Ferrari, 2009; Fedorov et al., 2010; Sriver and Huber, 2010; Sriver et al., 2010), thus potentially linking TC activity to the dynamics of the equatorial ocean. These linkages appear to be especially important in the Pacific basin, which exhibits relatively strong subtropical overturning and experiences the most TC activity. Interannual variability in upperocean properties in the equatorial Pacific has major implications for global climate through atmospheric teleconnections (i.e. El Niño-Southern Oscillation).

Previous modeling work has typically focused on climate responses to TC forcings on inter-annual to millennial time scales. The ocean's equatorial perturbation wave responses and resulting dynamical adjustment to individual TC events is largely unknown. Past observational work has pointed to a positive correlation between paired TC occurrences, symmetric about the equator, in the western Pacific and the eastward expansion of the tropical warm pool (Keen, 1982; Nitta, 1989). Strong surface wind forcing in the western Pacific, for example due to westerly wind events associated with the Madden-Julian Oscillation (MJO), can excite downwelling equatorial Kelvin waves (McPhaden, 1999). If the Kelvin waves are sufficiently nonlinear, they can induce an eastward expansion of the tropical Pacific warm pool leading to favorable conditions for El Niño development. In addition to Kelvin waves, intra-seasonal wind forcing can lead to strong current shear near the equator, which in turn is capable of exciting Yanai (or mixed Rossby gravity) waves. These waves, typically associated with tropical instabilities, induce significant mixing of the upper equatorial ocean, and they can influence near-surface energy dissipation rates, surface heat fluxes, and temperatures in the equatorial undercurrent and at the surface (Moum et al., 2009). Yanai waves also propagate energy vertically into the sub-thermocline ocean, and dissipation of these waves may be important for the formation of the deep equatorial circulation (Ascani et al., 2010).

Here we explore the possibility that TCs can generate equatorial Kelvin and Yanai waves using a global ocean general circulation model forced with TC winds, advancing previous work examining the global equilibrium ocean response to TC wind forcing (Sriver and Huber, 2010). We highlight a special case of 3 successive TCs occurring in the western North Pacific during May 2003. We frame the results in the context of developing a better understanding of how TCs can affect equatorial wave dynamics and possibly influence the initiation and magnitude of El Niño events.

\section{Methods}

We use an updated version of the ocean component of the Community Climate System Model (CCSM3) (Collins et al., 2006; Danabasoglu et al., 2006), which is based on the Parallel Ocean Program (POP v1.4.3) (Smith et al., 1992). We use the model configuration containing 100 and 116 grid points in the zonal and meridional directions, respectively, along with 25 vertical levels. The zonal grid spacing is constant, while the meridional grid spacing is variable with increased resolution $\left(1^{\circ}\right)$ near the equator. The vertical grid is also variable, with 17 of the 25 levels comprising the uppermost $1000 \mathrm{~m}$. Though we use the model's low-resolution configuration, coarse Arakawa B-grid ocean models (such as $\mathrm{POP}$ ) are capable of simulating realistic Kelvin waves ( $\mathrm{Ng}$ and Hsieh, 1994). The modified model includes recent improvements, such as the mesoscale eddy flux parameterization (Ferrari et al., 2008), which properly represents fluxes in the surface boundary layer (Danabasoglu et al., 2008). Other model features have been documented extensively, and we refer the reader elsewhere for a complete model description (Smith and Gent, 2004).

Atmospheric input to the ocean model is based on the interannual bulk forcing of Large and Yeager (2004). We have modified the atmospheric forcing (years 1994-2000) to include TC wind fields for all events globally between 2000 and 2006, as defined by the Best Track data set. TC wind fields are derived from QuikScat satellite estimates. We performed multiple $\sim 500 \mathrm{yr}$ spin-up simulations for several idealized TC wind forcing factors, where we increased the magnitude of the TC wind fields by $1 \mathrm{X}, 2 \mathrm{X}$, and $3 \mathrm{X}$. In all runs, we recycle the 7-yr period atmospheric forcing fields for the entire $500 \mathrm{yr}$. To account for potential biases and model drift, modeled results are presented as anomalies referenced to a control simulation in which TC wind fields are omitted.

As described in Sriver and Huber (2010), limitations of this modeling technique include (1) lack of satellite coverage during TC events, (2) unreliable QuikScat wind estimates above $50 \mathrm{~m}$ per second - thus no winds above category two, (3) smoothing of TC wind fields during interpolation to the model grid, and (4) inadequate ocean model mixing parameterizations for extreme wind forcing. Each of these limitations introduces a systematically low bias in TCocean effects. Therefore, the modified model with the $1 \mathrm{X}$ TC forcing underestimates the TC-induced surface cooling and mixed layer deepening, compared to along-track estimates and global climatologies derived using surface temperature fields from reanalysis (Sriver and Huber, 2007) and satellites (Sriver et al., 2008). As noted previously, to account for these biases we systematically apply multiple scale factors to the $\mathrm{TC}$ wind fields. The $2 \mathrm{X}$ scale factor (doubling the satellite 
wind estimates) yields the closest general fit to observed climatologies of the upper-ocean response to TC wind forcing (Sriver and Huber, 2010). The scale factor affects the overall magnitude of the upper-ocean response, but we find the general characteristics of the wave response are robust to the different scale factors applied to the TC wind forcing (e.g. 1X, $2 \mathrm{X}, 3 \mathrm{X})$.

We focus on a particular case where three successive TC events in the northwestern Pacific basin (Fig. 1) initiate a transient equatorial wave response in the ocean model. All three TCs originate within a span of 8 days, between 17 and 25 May 2003. We highlight this case, because it represents the most pronounced wave response in the model during the forcing years.

As a consequence of our methodological choices, such as recycling the forcing data set every $7 \mathrm{yr}$ and arbitrarily adjusting TC winds, our approach is somewhat idealized. It is difficult to translate between the modeled result and reality, because the background atmospheric forcing fields (19942000) used in the model do not correspond to the global TC wind fields (2000-2006). Our choice of methodology, and the associated inconsistency, is due to the unavailability of $\mathrm{TC}$ winds and interannual atmospheric bulk-forcing fields for corresponding years. For instance, the 2003 TC events highlighted in this study are combined with atmospheric fields from 1997 in the model. The large-scale atmospheric fields mark a transitional period toward the strong 1997-1998 El Niño event. This approach should capture the essence of the physical processes and responses at play, but the connection to specific observed dates and events is somewhat tenuous.

\section{Results and discussion}

The sequence of TC events shown in Fig. 1 excites a transient wave response in the equatorial thermocline represented by an eastward-propagating warm temperature anomaly compared to the control simulation (Fig. 2; animation available in the supplemental information). The modeled wave disturbance is triggered directly by the enhanced wind forcing, as it originates during the TC events. It is possible that thermodynamic effects associated with vertical mixing and wake recovery may also play a role in wave formation, but our methodology cannot adequately account for these effects due to lack of ocean-atmosphere coupling.

Initially, the oceanic response to the TC wind forcing is characterized by a warm anomaly between 100 and $200 \mathrm{~m}$ depth in the western equatorial Pacific, which begins to propagate eastward. The motion is indicated by anomalous zonal velocity contours overlaying the positive temperature anomaly (Fig. 2). The wave evolves with nonlinear Kelvin wave-like characteristics, which allows for zonal heat and mass transport through geostrophic adjustment of the heat anomaly within a sloping thermocline (Le Sommer and Zeitlin, 2005). After 10 days, a baroclinic Yanai wave

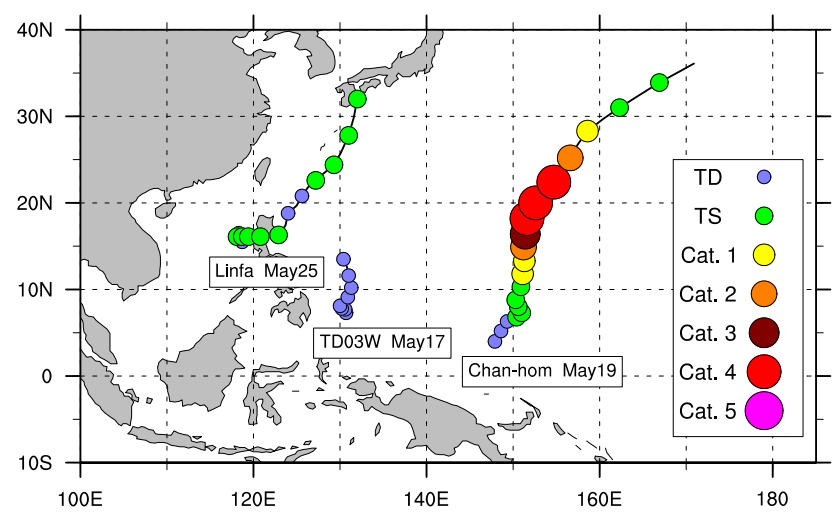

Fig. 1. TC tracks occurring near the location and time of onset of the modeled Kelvin and Yanai wave combination according to "Best Track" estimates. Colored circles denote storm intensity according to the Saffir-Simpson intensity scale (TD - Tropical Depression, TS - Tropical Storm).

becomes visible behind the Kelvin wave (Figs. 2 and 3a). The Yanai wave is characterized by out-of-phase temperature and zonal velocity anomalies on either side of the equator. The Kelvin and Yanai wave components evolve according to their respective wave equations, and they separate completely after $\sim 30$ days. The Yanai wave travels slower than the Kelvin wave (Fig. 3a), and its group velocity corresponds roughly to the first baroclinic mode for the mixed Rossby-gravity wave (Moore et al., 1998). After $\sim 45$ days, the Kelvin wave reaches the eastern boundary, where the anomalous heat carried by the wave rises to the surface and is partially transported poleward along the boundary.

Past observational studies have highlighted the connections between TC pairs (symmetric about the equator) and the changes in tropical Pacific surface temperature patterns related to El Niño-Southern Oscillation (Keen, 1982; Nitta, 1989). The results presented here mark the first time equatorial Kelvin waves have been generated by realistic simulation of TC wind forcing in a global ocean general circulation model. Furthermore, the wind forcing shown here differs from various other documented occurrences (Keen, 1982; Nitta, 1989), in that it involves three sequential events in the same hemisphere rather than paired events on opposite sides of the equator. The wave response is consistent with previous modeling work examining nonlinear Kelvin waves under idealized asymmetric forcing conditions (Fedorov and Melville, 2000).

The modeled Kelvin and Yanai waves (Fig. 2) show how wind forcing by a combination of TCs can significantly alter equatorial ocean dynamics in a coarse ocean general circulation model. However, this result may have no relevance to nature unless it is observable. To test this, we compare longitude versus time plots of the modeled temperature and zonal velocity anomalies with anomalous ocean heat observations from the Tropical Atmosphere Ocean (TAO) buoy array for 
A

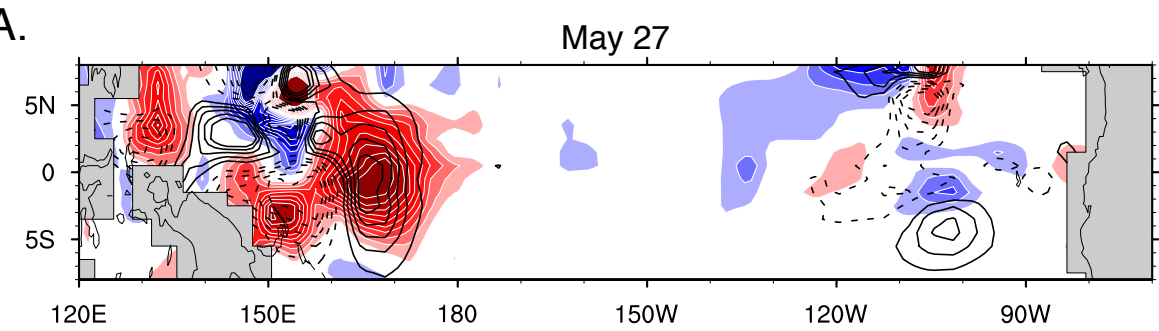

B.

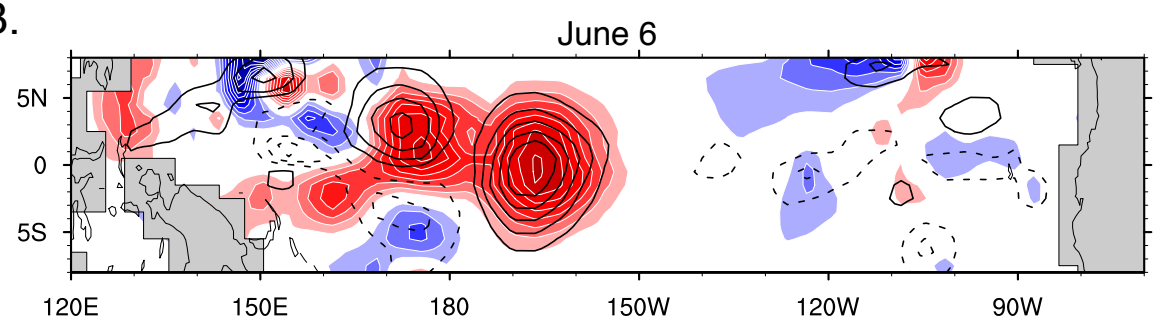

C.

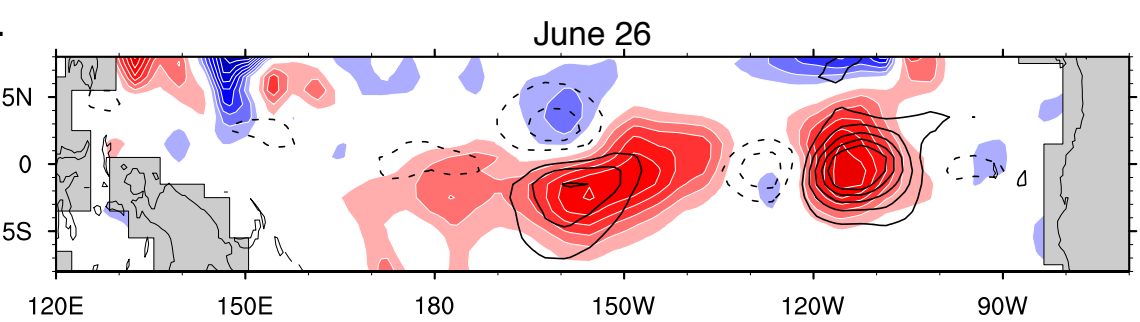

D.

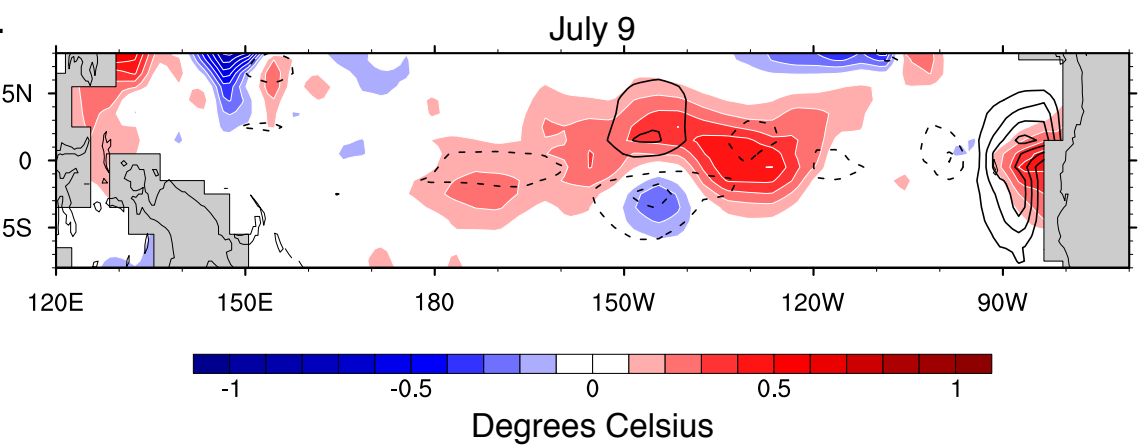

Fig. 2. Upper ocean temperature difference (color contours) between the simulation with $\mathrm{TC}$ wind forcing (2X scale factor) and the control for: (A) 27 May 2003, (B) 6 June 2003, (C) 26 June 2003, and (D) 9 July 2003. In all panels, the mean difference between the TC simulation and control has been removed to highlight the transient features. The black contours represent anomalous zonal (eastward) velocity (dashed lines denote negative values). Zonal velocity contour spacing is $2 \mathrm{~cm} \mathrm{~s}^{-1}$. Both quantities are averaged between 100 and $200 \mathrm{~m}$ depth.

the same time period following the three TC events in 2003 (Fig. 3). Analysis of the TAO buoys shows a warm ocean heat anomaly, compared to climatology, in the upper $300 \mathrm{~m}$ moving eastward across the equatorial Pacific. The average modeled ocean heat anomaly/transport in Fig. 3a corresponds to roughly $1 / 4$ of the observed average ocean heat anomaly in Fig. 3b. While the full structure of the modeled wave is not evident in the observations, the eastward-propagating heat content anomaly does reflect the general characteristics of a nonlinear Kelvin wave with a translational speed slightly slower than the modeled wave.

As a cross-check on the TAO buoy observations, we analyze sea-level anomalies (SLA) between May and July 2003, using the SSALTO/DUACS multi-mission altimeter products obtained through AVISO (Archiving, Validation, and Interpretation of Satellite Oceanographic Data, http://www.aviso. oceanobs.com). SLAs are calculated daily, and the altimetry product combines data from up to four satellites at any given time. This method of merging data from multiple satellites has been shown to improve skill in capturing mesoscale variability (Pascual et al., 2006). SLAs are a good indicator of anomalous ocean heat content in the upper ocean. The SLAs in Fig. 4a show an eastward propagating anomaly in equatorial Pacific sea-level, corresponding to a positive ocean heat content anomaly. The wave-like structure is consistent with the TAO observations and the CCSM model results shown 

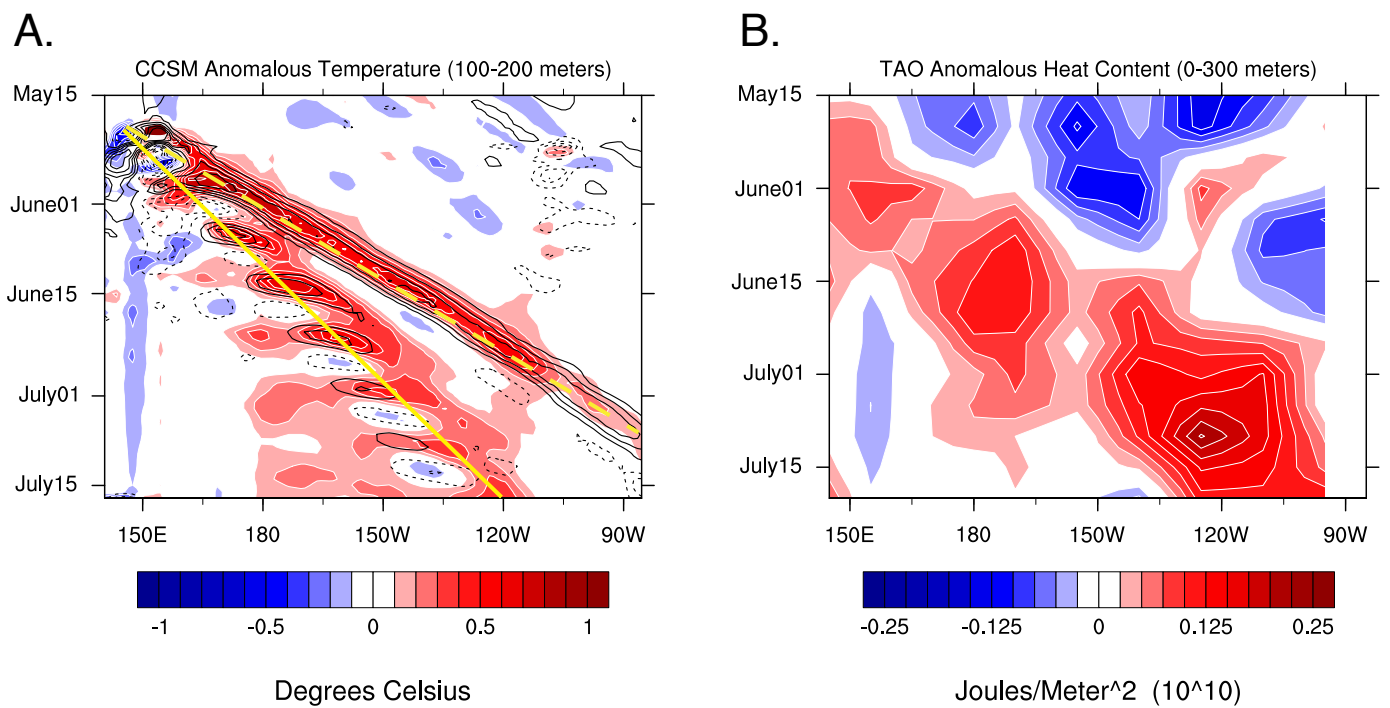

Fig. 3. (A) Longitude-time plot of the anomalous temperature and zonal velocity shown in Fig. 2 averaged between 0 and $+5^{\circ} \mathrm{N}$. The yellow dashed line denotes the Kelvin wave velocity. The solid yellow line is the Yanai wave group velocity for the first baroclinic mode scaled by the Kelvin wave speed. The estimated modeled Kelvin and Yanai wave speeds are $\sim 3.1$ and $\sim 2.3 \mathrm{~m} \mathrm{~s}^{-1}$, respectively. (B) Longitude-time plot of observed, anomalous upper ocean heat content (compared to climatology) from the TAO buoy array. Ocean heat content is averaged between -2 and $+2^{\circ} \mathrm{N}$, and integrated to $300 \mathrm{~m}$ depth. The time interval is 15 May-15 July 2003, corresponding to the same modeled interval shown in Fig. 3a. The estimated observed Kelvin wave speed is $\sim 2.9 \mathrm{~m} \mathrm{~s}^{-1}$. Both the modeled and observed Kelvin wave speeds are within the range of documented wave observations from the TAO array (Shinoda et al., 2008).

in Fig. 3. Using satellite-derived SLAs, we can also approximate zonal and meridional anomalies in geostrophic currents using the relations:

$u_{g}^{\prime}=-\frac{g}{f} \frac{\partial \mathrm{SLA}}{\partial y}$

$v_{g}^{\prime}=\frac{g}{f} \frac{\partial \mathrm{SLA}}{\partial x}$

where $u_{g}^{\prime}$ and $v_{g}^{\prime}$ are the zonal and meridional geostrophic current anomalies, respectively, $g$ is the gravitational acceleration, and $f$ is the Coriolis parameter. The zonal geostrophic current anomalies (Fig. 4b) are generally consistent with the modeled and observed spatial and temporal structures of the upper-ocean temperature anomalies shown in Fig. 3. However, the geostrophic anomalies in the meridional velocity (Fig. 4c) show no clear wave response, suggesting TCinduced waves are incapable of affecting meridional transports and/or the fine-scale structure of the relatively weak zonal SLA gradients are not captured in the altimetry product. Regardless of the limitations in current velocity anomalies derived from altimetry, the observed ocean heat content and SLAs (Figs. $3 \mathrm{~b}$ and $4 \mathrm{a}$ ) provide additional independent support to the idea that TC wind forcing excites equatorial ocean waves.

In our model experiment, we consistently find an equatorial wave response to $\mathrm{TC}$ forcing in the western and central Pacific. The waves are typically damped out quickly, and the situation highlighted here represents the best example of a basin-scale Kelvin/Yanai wave combination during the
7 -yr forcing cycle. It is not possible to directly attribute the observed equatorial heat anomaly (Fig. 3) and SLA/current anomalies (Fig. 4) to TC wind forcing because of the somewhat idealized nature of our simulations. As discussed in the methods section, the modeled wave is simulated using TC events from 2003 blended into global atmospheric forcing from 1997, representing conditions prior to the onset of the large amplitude 1997-1998 El Niño event. It has previously been documented (McPhaden, 1999) that a series of strong westerly wind events during the spring and summer of 1997, associated with the Madden-Julian Oscillation, played an important role in initiating this El Niño event, leading to eastward expansion of the tropical Pacific warm pool. These conditions are also captured in the bulk forcing fields used in our model experiment, in that the control simulation reproduces the main characteristics of the observed zonal redistribution of ocean heat in the tropical Pacific during 1997 (not shown). Thus, we interpret the modeled waves to be the result of superimposing TC wind fields on a background state transitioning toward El Niño conditions. These background conditions may be more conducive to wave development in the model. This finding appears to be more of a model limitation rather than a natural requirement, since the observed TC-induced waves in 2003 (Figs. 3 and 4) occur during a transition period from El Niño to neutral conditions in the eastern equatorial Pacific.

The interannual variability in the large-scale atmospheric bulk forcing fields may be responsible for the model's wave 

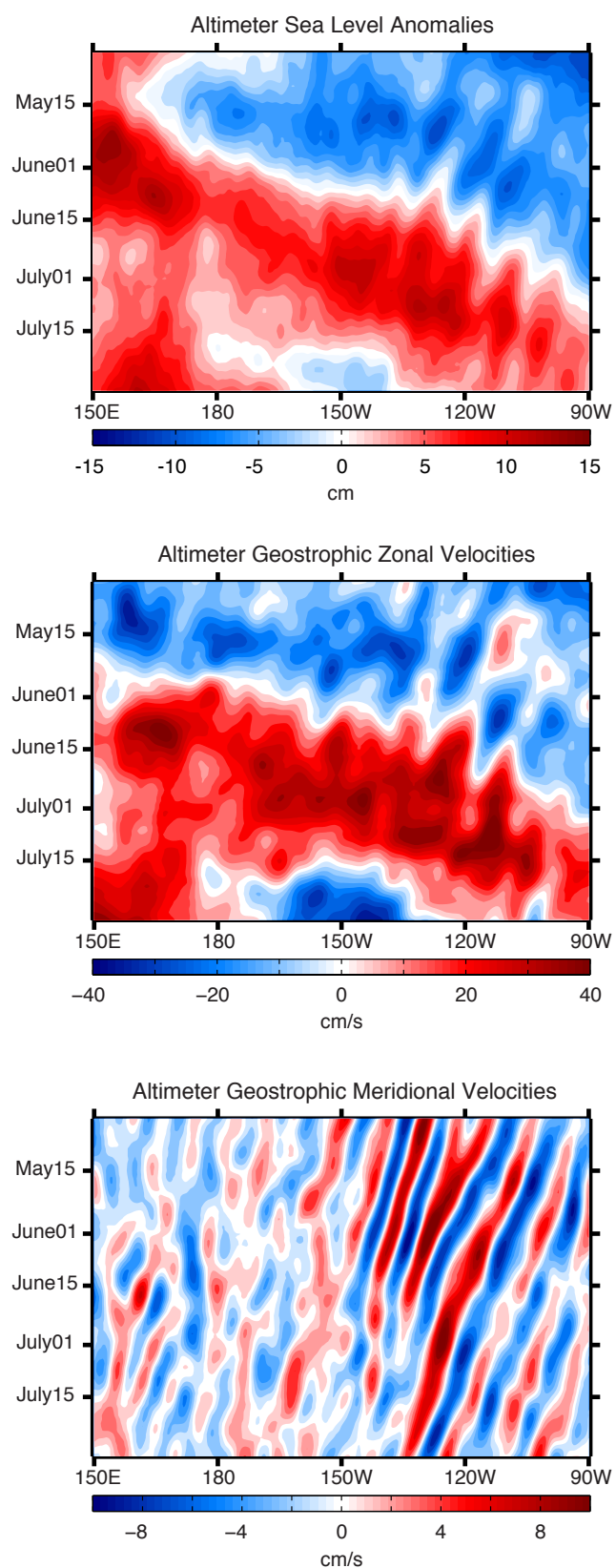

Fig. 4. Longitude-time plots of anomalous daily (A) sea-level height, (B) geostrophic zonal velocity (eastward positive), and (C) geostrophic meridional velocity (northward positive), derived from the SSALTO/DUACS multi-satellite altimetry data product. Sea-level height and geostrophic zonal velocity anomalies are averaged between -2 and $+2^{\circ} \mathrm{N}$, and geostrophic meridional velocity anomalies are averaged between -5 and $+5^{\circ} \mathrm{N}$. All quantities are spatially filtered using a $2-\mathrm{D} 1.65^{\circ}$ mean filter.

preference during conditions consistent with a transition to $\mathrm{El}$ Niño, which leads us to consider more generally the differences in the model's background ocean state during this forcing year compared to other years in the 7-yr forcing cycle. We find the modeled TC-induced wave response is sensitive

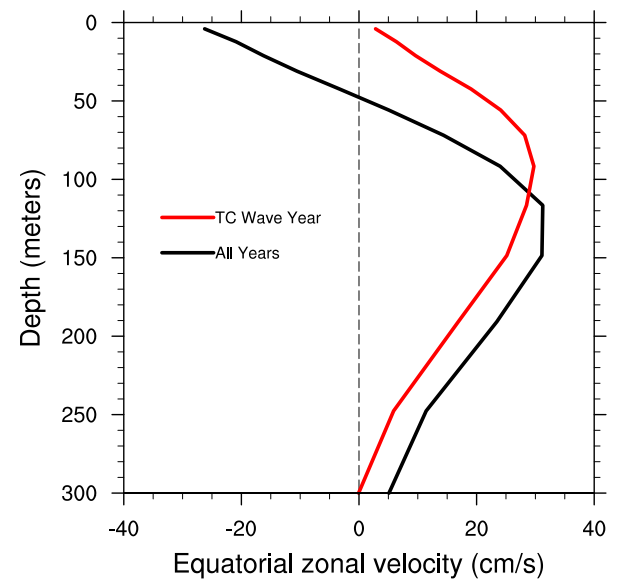

Fig. 5. Vertical profile of the modeled zonal current velocity in the equatorial Pacific between -5 and $+5^{\circ} \mathrm{N}$. The black curve denotes the annual average over the $7 \mathrm{yr}$ forcing cycle (all years). The red curve represents the annual average during the model year with 1997 atmospheric forcing conditions (TC wave year), reflecting anomalously small vertical current shear in the background state compared to the mean.

primarily to the vertical structure of the equatorial zonal currents. During the 1997 forcing year, the background ocean state features significantly reduced vertical shear in the equatorial Pacific zonal velocity, compared to the annual average over all forcing years (Fig. 5). Current shear is reduced as warm western Pacific surface temperature expands eastward, depressing zonal temperature gradients near the surface. Strong vertical shear of zonal currents has been shown to inhibit waves in ocean models due to enhanced frictional effects (Giese and Harrison, 1990). Thus, the anomalously small background shear conditions provide a favorable environment for equatorial wave excitation and propagation in the model, though it may not be a necessary criterion for such waves in nature (as suggested by Figs. 3 and 4). The general similarity between the model results and observations is consistent with the hypothesis that TCs are capable of exciting equatorial waves, given the limitations associated with using a coarse-resolution ocean-only modeling framework.

Considering the observational relationship between earlyseason TC occurrence and El Niño onset (e.g. Nitta, 1989), findings shown in Figs. 3 and 4 provide evidence form both an ocean model and observations for the importance of direct TC wind forcing in initiating El Niño events via Kelvin wave excitation. The modeling evidence is supported by the skill of the CCSM3 ocean component in reproducing the tropical Pacific mean state and annual cycle (Fig. 6), given our current modeling configuration using the interannual bulk forcing fields of Large and Yeager (2004). The annual cycle of tropical Pacific sea surface temperature is calculated for the model simulations (control and the TC2X case) and ocean reanalysis from the European Centre for Medium-Range Weather 

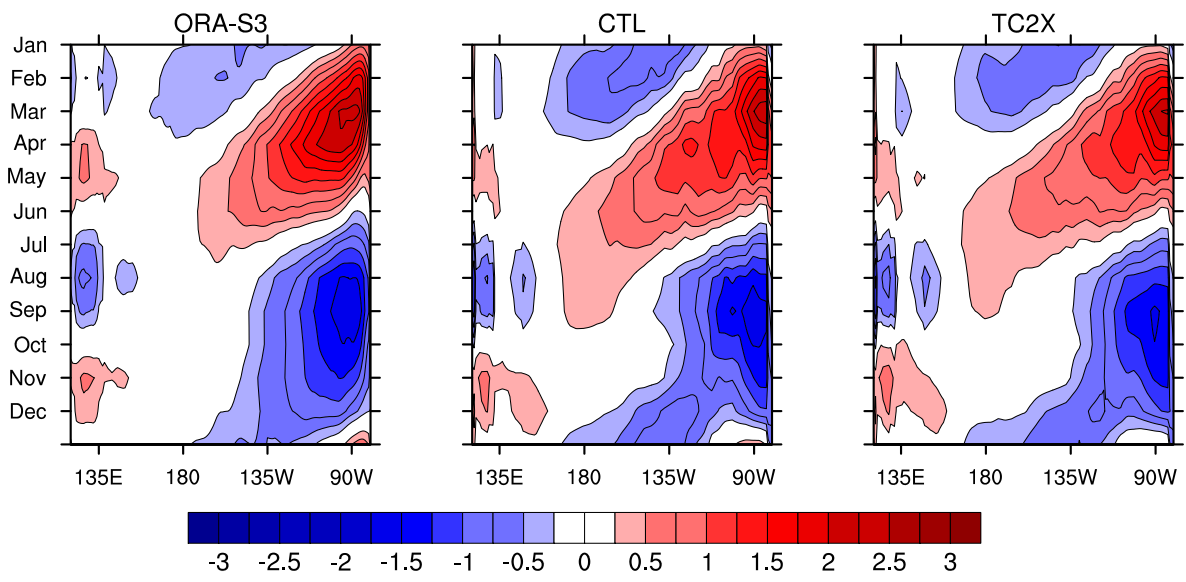

\begin{tabular}{lllllllllllll}
-3 & -2.5 & -2 & -1.5 & -1 & -0.5 & 0 & 0.5 & 1 & 1.5 & 2 & 2.5 & 3 \\
\multicolumn{8}{c}{ Celsius }
\end{tabular}

Fig. 6. Longitude-time plots of the annual cycle of sea surface temperature anomalies in the equatorial Pacific (between -5 and $5^{\circ} \mathrm{N}$ ) relative to the long-term mean, for (A) European Centre for Medium-Range Weather Forecasts (ECMWF) Ocean Re-Analysis (ORA-S3) product (Balmaseda et al., 2008), (B) the CCSM control simulation with the standard atmospheric forcing, and (C) the CCSM simulation with TC winds scaled by $2 \mathrm{X}$. The annual cycle is calculated over the period 1960-2009 for ORA-S3 and over the 7 yr of model cycle for the CCSM simulations, reflecting large-scale atmospheric forcing conditions corresponding to 1994-2000.
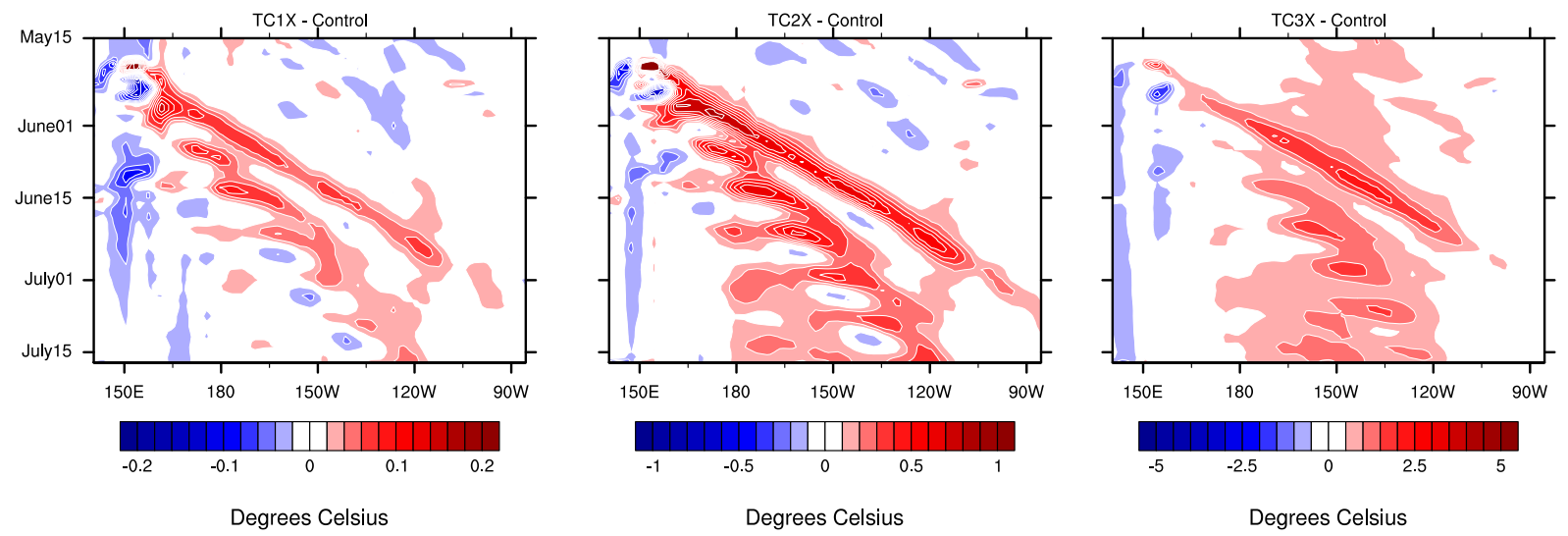

Fig. 7. Longitude-time plots of modeled daily temperature anomalies averaged between 0 and $+5^{\circ} \mathrm{N}$ and $100-200 \mathrm{~m}$ depth for CCSM simulations with different scaling factors applied to the TC wind speed estimates derived from QuikScat: (A) 1X, (B) 2X, and (C) 3X. Anomalies in all plots are calculated relative to the control simulation and the mean difference has been removed as in Fig. 3a. Note the general wave characteristics are consistent between cases, but the magnitude of the temperature response increases with TC wind speed.

Forecasts (ECMWF) Ocean Re-Analysis (ORA-S3) product (Balmaseda et al., 2008). Figure 6 demonstrates that the model reproduces the main characteristics of the annual cycle compared to the reanalysis, including the asymmetric structure between the east and west Pacific, supporting the use of this model in analyzing tropical upper-ocean dynamics. It also supports our methodological choice in using a repeating 7-yr cycle for calculating a climatology, given that the relatively small subset of repeating years in the model simulations reproduces the reanalysis based on $\sim 40 \mathrm{yr}$ of observations. Furthermore, the annual cycle for the case with enhanced TC winds is generally consistent with both the control case and the reanalysis, indicating that the impact of the transient waves does not affect the modeled mean state.
This version of the ocean component of CCSM3 has been analyzed and evaluated much more extensively elsewhere (Bryan et al., 2006; Danabasoglu et al., 2006, 2008; Yeager et al., 2006; Griffies et al., 2009), and we refer the reader to those publications for additional documentation of model skill.

We examine the sensitivity of the amplitude of the modeled wave to the magnitude of the TC winds, by comparing model results for different scale factors applied to the TC wind speeds. As shown in Fig. 7, wave amplitude is directly proportional to TC wind speed, and the wave response is reduced for the $1 \mathrm{X}$ scenario. The $1 \mathrm{X}$ scenario represents TC wind speeds derived from QuikScat with no scaling correction, but these estimates are consistently negatively biased 
due to Quikscat limitations. Applying a 2X scale factor has been shown to capture more accurately the upper-ocean mixing response in this model (e.g. mixed layer deepening and surface temperature cooling) (Sriver and Huber, 2010). Regardless of the scale factor ( $1 \mathrm{X}$ or $2 \mathrm{X}$ ), the general characteristics of the modeled waves are robust. Figure 7 highlights the importance of the anomalous TC winds in inducing the wave response, rather than background variability in the climatological wind forcing (e.g. westerly wind events) being the main factor. The addition of the transient TC wind fields to the climatological fields generates a pronounced wave response for all scale factors relative to the control simulations, and the amplitude of the wave train is sensitive to the strength of TC wind forcing.

The potential link between TCs and equatorial waves has important implications for equatorial dynamics, mixing budgets, and transport. Consistent with recent analysis (Ascani et al., 2010), the modeled Yanai wave propagates energy vertically to the ocean floor, which can result in mixing and chaotic stirring in the intermediate and deep equatorial ocean (Li and Pacanowski, 1996). It is hypothesized that dissipation of these waves is important for the formation of deep equatorial circulations (Ascani et al., 2010). Yanai waves also lead to strong vertical mixing in the near-surface equatorial oceans due to current shear instabilities. Mixing induced by these waves has been shown to affect dissipation rates and surface heat fluxes that can cool the surface and warm the equatorial undercurrent (Moum et al., 2009). Furthermore, an additional wave source will likely influence tropical instability wave activity, which is linked to Yanai wave occurrence (Zhou and Boyd, 2009), though the limited model resolution of the present study prohibits specific identification of these effects. Our results suggest that in addition to known processes, such as periodic wind forcing, boundary effects, and current shear, TCs may provide a heretofore unrecognized mechanism capable of influencing equatorial wave dynamics near the surface with implications for the dynamics of the intermediate and deep equatorial ocean.

\section{Conclusions}

These results show a direct causal connection between 3 successive TC events and the excitation of equatorial ocean waves in an ocean model. The modeled waves are consistent with observations from the TAO array and SLA derived from altimetry, providing evidence that transient wind forcing by TCs can influence the zonal redistribution of heat in the upper equatorial Pacific ocean via Kelvin wave excitation.

The modeled wave response shown here highlights our best example of basin-scale waves generated during the $7 \mathrm{yr}$ TC forcing time series. In other instances, TC winds generate equatorial waves that are subsequently damped and have little apparent impact on heat or momentum budgets. Our results indicate that TC forcing is capable of affecting equatorial wave dynamics, but, in the model, the effect only leads to the combination of basin-scale Kelvin and Yanai waves for background forcing conditions featuring anomalously small vertical current shear.

The possibility that individual or sequential TC events could have an impact on tropical wave dynamics through excitation or amplification of Kelvin and Yanai waves has interesting implications for climate variability. These waves affect mixing and energy budgets of the equatorial oceans, and they are important for meridional and horizontal transports, excitation of tropical instability waves, and the formation of deep equatorial circulations. Equatorial Kelvin and Yanai waves are also responsible for the zonal rearrangement of heat content via thermocline adjustment, thus making western Pacific TCs potentially important triggering mechanisms during the initial adjustment toward El Niño conditions. Our results suggest TCs in the western Pacific could influence the timing and amplitude of El Niño events.

This paper provides a conceptual framework for how TCs may influence tropical Pacific ocean waves, and thus ENSO, using a comprehensive ocean model and idealized (though still based on real observations) TC surface forcing. More analysis is needed to examine potential relationships between TC wind forcing and upper ocean equatorial waves, utilizing more idealized and/or self-consistent modeling frameworks, in order to develop a deeper understanding of possible connections between ENSO and climate.

\section{Supplementary material related to this article is available online at: http://www.earth-syst-dynam.net/4/ 1/2013/esd-4-1-2013-supplement.zip.}

Acknowledgements. This work was supported by grant NSF ATM 0741797 to M. Huber. R. Sriver's research was partially supported by the NOAA Climate and Global Change Postdoctoral Fellowship Program, administered by the University Corporation for Atmospheric Research. Léon Chafik is supported by the Swedish National Space Board. The authors acknowledge helpful discussions with Kerry Emanuel, Jenni Evans, Raffaele Ferrari, and Marlos Goes. Observational ocean data were made available by the TAO Project Office of NOAA/PMEL. The altimeter products were produced by Ssalto/Duacs and distributed by Aviso with support from CNES (http://www.aviso.oceanobs.com/duacs/). QuikScat data are produced by Remote Sensing Systems (www.remss.com) and sponsored by the NASA Ocean Vector Winds Science Team. We gratefully acknowledge the European Centre for MediumRange Weather Forecasts in creating the ocean (ORA-S3) and atmosphere (ERA-40) reanalysis products. Reanalysis products were downloaded via the Asia-Pacific Data-Research Center (APDRC) of the International Pacific Research Center (IPRC) (http://apdrc.soest.hawaii.edu). The authors acknowledge the use of the NCAR Command Language (NCL) in the data analysis and visualization herein. This is PCCRC paper \#1220.

Edited by: G. Lohmann 


\section{References}

Ascani, F., Firing, E., Dutrieux, P., McCreary, J. P., and Ishida, A.: Deep equatorial ocean circulation induced by a forceddissipated yanai beam, J. Phys. Oceanogr., 40, 1118-1142, doi:10.1175/2010JPO4356.1, 2010.

Balmaseda, M. A., Vidard, A., and Anderson, D. L. T.: The ECMWF ocean analysis system: ORA-S3, Mon. Weather Rev., 136, 3018-3034, 2008.

Bryan, F. O., Danabasoglu, G., Nakashiki, N., Yoshida, Y., Kim, D.-H., Tsutsui, J., and Doney, S. C.: Response of the North Atlantic Thermohaline circulation and ventilation to increasing carbon dioxide in CCSM3, J. Climate, 19, 2382-2397, 2006.

Collins, W. D., Bitz, C. M., Blackmon, M. L., Bonan, G. B., Bretherton, C. S., Carton, J. A., Chang, P., Doney, S. C., Hack, J. J., Henderson, T. B., Kiehl, J. T., Large, W. G., McKenna, D. S., Santer, B. D., and Smith, R. D.: The community climate system model version 3 (CCSM3), J. Climate, 19, 2122-2143, 2006.

Danabasoglu, G., Large, W. G., Tribbia, J. J., Gent, P. R., Briegleb, B. P., and McWilliams, J. C.: Diurnal coupling in the tropical oceans of CCSM3, J. Climate, 19, 2347-2365, 2006.

Danabasoglu, G., Ferrari, R., and McWilliams, J. C.: Sensitivity of an ocean general circulation model to a parameterization of near-surface eddy fluxes, J. Climate, 21, 1192-1208, doi:10.1175/2007JCLI1508.1, 2008.

Emanuel, K. A.: The contribution of tropical cyclones to the oceans' meridional heat transport, J. Geophys. Res., 106, 14771-14782, 2001.

Emanuel, K. A.: Increasing destructiveness of tropical cyclones over the past 30 years, Nature, 436, 686-688, doi:10.1038/nature03906, 2005.

Fedorov, A. V. and Melville, W. K.: Kelvin fronts on the equatorial thermocline, J. Phys. Oceanogr., 30, 1692-1705, 2000.

Fedorov, A. V., Brierley, C. M., and Emanuel, K.: Tropical cyclones and permanent El Niño in the early Pliocene epoch, Nature, 463, 1066-1070, doi:10.1038/nature08831, 2010.

Ferrari, R., McWilliams, J. C., Canuto, V. M., and Dubovikov, M.: Parameterization of eddy fluxes near oceanic boundaries, J. Climate, 21, 2770-2789, doi:10.1175/2007JCLI1510.1, 2008.

Giese, B. S. and Harrison, D. E.: Aspects of the Kelvin wave response to episodic wind forcing, J. Geophys. Res., 95, 72897312, 1990.

Griffies, S. M., Biastoch, A., Boning, C., Bryan, F., Danabasoglu, G., Chassignet, E. P., England, M. H., Gerdes, R., Haak, H., Hallberg, R. W., Hazeleger, W., Jungclaus, J., Large, W. G., Madec, G., Pirani, A., Samuels, B. L., Scheinert, M., Gupta, A. S., Severijns, C. A., Simmons, H. L., Treguier, A. M., Winton, M., Yeager, S., and Yin, J.: Coordinated ocean-ice reference experiments (COREs), Ocean Model., 26, 1-46, 2009.

Hart, R. E.: An inverse relationship between aggregate northern hemisphere tropical cyclone activity and subsequent winter climate, Geophys. Res. Lett., 38, L01705, doi:10.1029/2010GL045612, 2011.

Hu, A. and Meehl, G. A.: Eff ect of the Atlantic hurricanes on the oceanic meridional overturning circulation and heat transport, Geophys. Res. Lett., 36, L03702, doi:10.1029/2008GL036680, 2009.

Jansen, M. and Ferrari, R.: The impact of the latitudinal distribution of tropical cyclones on ocean heat transport, Geophys. Res. Lett., 36, L06604, doi:10.1029/2008GL036796, 2009.
Keen, R. A.: The role of cross-equatorial tropical cyclone pairs in the Southern Oscillation, Mon. Weather Rev., 110, 1405-1416, 1982.

Korty, R. L., Emanuel, K. A., and Scott, J. R.: Tropical cycloneinduced upper-ocean mixing and climate: Application to equable climates, J. Climate, 21, 638-654, 2008.

Large, W. G. and Yeager, S. G.: Diurnal to decdal global forcing for ocean and sea-ice models: the data sets and flux climatologies, NCAR Technical Note, NCAR/TN-460+ STR, National Center for Atmospheric Research, Boulder, Colorado, USA, 105 pp., 2004.

Le Sommer, J. and Zeitlin, V.: Tracer transport during the geostrophic adjustment in the equatorial ocean, in: Chaotic Dynamics and Transport in Classical and Quantum Systems, edited by: Collet, P., Courbage, M., Metens, S., Neishtadt, A., and Zaslavsky, G., Kluwer Academic Publishers, The Netherlands, 413-429, 2005.

Li, X., Chang, P., and Pacanowski, R. C.: A wave-induced stirring mechanism in the mid-depth equatorial ocean, J. Mar. Res., 54, 487-520, 1996.

Manucharyan, G. E., Brierley, C. M., and Fedorov, A. V.: Climate impacts of intermittent upper ocean mixing induced by tropical cyclones, J. Geophys. Res., 116, C11038, doi:10.1029/2011JC007295, 2011.

McPhaden, M. J.: Genesis and Evolution of the 1997-98 El Niño, Science, 283, 950-954, 1999.

Moore, D. W., Kloosterziel, R. C., and Kessler, W. S.: Evolution of mixed Rossby gravity waves, J. Geophys. Res., 103, 5331-5346, 1998.

Moum, J. N., Lien, R.-C., Perlin, A., Nash, J. D., Gregg, M. C., and Wiles, P. J.: Sea surface cooling at the equator by subsurface mixing in tropical instability waves, Nat. Geosci., 2, 761-765, doi:10.1038/NGEO657, 2009.

Ng, M. K. F. and Hsieh, W. W.: The equatorial Kelvin wave in finite diff erence models, J. Geophys. Res., 99, 14173-14185, 1994.

Nitta, T.: Development of a twin cyclone and westerly bursts during the initial phase of the 1986-1987 El Niño, J. Meteorol. Soc. Jpn., 67, 677-681, 1989.

Pascual, A., Faugère, Y., Larnicol, G., and Le Traon, P. Y.: Improved description of the ocean mesoscale variability by combining four satellite altimeters, Geophys. Res. Lett., 33, L02611, doi:10.1029/2005GL024633, 2006.

Pasquero, C. and Emanuel, K.: Tropical cyclones and transient upper-ocean warming, J. Climate, 21, 149-162, doi:10.1175/2007JCLI1550.1, 2008.

Scoccimarro, E., Gualdi, S., Bellucci, A., Sanna, A., Fogli, P. G., Manzini, E., Vichi, M., Oddo, P., and Navarra, A.: Eff ects of tropical cyclones on ocean heat transport in a high-resolution coupled general circulation model, J. Climate, 24, 4368-4384, 2011.

Shinoda, T., Roundy, P. E., and Kiladis, G. N.: Variability of intraseasonal Kelvin waves in the equatorial Pacific Ocean, J. Phys. Oceanogr., 38, 921-944, 2008.

Smith, R. D. and Gent, P. R.: Reference manual for the Parallel Ocean Program (POP), ocean component of the Community Climate System Model (CCSM2.0 and 3.0), Los Alamos National Laboratory Technical Report, LA-UR-02-2484, Los Alamos National Laboratory, Los Alamos, New Mexico, 75 pp., 2004. 
Smith, R. D., Dukowicz, J. K., and Malone, R. C.: Parallel ocean general circulation modeling, Physica D, 60, 38-61, 1992.

Sobel, A. H. and Camargo, S. J.: Influence of western north Pacific tropical cyclones on their large-scale environment, J. Atmos. Sci., 62, 3396-3407, 2005.

Sriver, R. L. and Huber, M.: Low frequency variability in globally integrated tropical cyclone power dissipation, Geophys. Res. Lett., 33, L11705, doi:10.1029/2006GL026167, 2006.

Sriver, R. L. and Huber, M.: Observational evidence for an ocean heat pump induced by tropical cyclones, Nature, 447, 577-580, doi:10.1038/nature05785, 2007.

Sriver, R. L. and Huber, M.: Modeled sensitivity of upper thermocline properties to tropical cyclone winds and possible feedbacks on the Hadley circulation, Geophys. Res. Lett., 37, L08704, doi:1029/2010GL042836, 2010.

Sriver, R. L., Huber, M., and Nusbaumer, J.: Investigating tropical cyclone-climate feedbacks using the TRMM Microwave Imager and the Quick Scatterometer, Geochem. Geophy. Geosy., 9, Q09V11, doi:1029/2007GC001842, 2008.
Sriver, R. L., Goes, M., Mann, M. E., and Keller, K.: Climate response to tropical cyclone induced ocean mixing in an Earth system model of intermediate complexity, J. Geophys. Res., 115, C10042, doi:10.1029/2010JC006106, 2010.

Trenberth, K. E. and Fasullo, J.: Water and energy budgets of hurricanes and implications for climate change, J. Geophys. Res., 112, D23107, doi:10.1029/2006JD008304, 2007.

Vecchi, G. A., Swanson, K. L., and Soden, B. J.: Whither hurricane ativity?, Science, 322, 687-689, 2008.

Vincent, E. M., Lengaigne, M., Madec, G., Vialard, J., Samson, G., Jourdain, N. C., Menkes, C. E., and Jullien, S.: Processes setting the characteristics of sea surface cooling in duced by tropical cyclones, J. Geophys. Res., 117, C02020, doi:10.1029/2011JC007396, 2012.

Yeager, S. G., Shields, C. A., Large, W. G., and Hack, J. J.: The low-resolution CCSM3, J. Climate, 19, 2545-2566, 2006.

Zhou, C. and Boyd, J. P.: Nonlinear shallow water tropical instability waves on the equatorial $\beta$-plane: Genesis of two distinct types of waves, Geophys. Res. Lett., 36, L23605, doi:10.1029/2009GL040499, 2009. 